\title{
Maya BURGER, Claude CAlAME, (éds.), Comparer les comparatismes. Perspectives sur l'histoire et les sciences des religions
}

Paris, Milan, Edidit Archè, coll. « Histoire de l'histoire des religions ", 2, 2006, $238 \mathrm{p}$.

\section{Regis Le Mer}

\section{(2) OpenEdition} Journals

Édition électronique

URL : http://journals.openedition.org/assr/21540

DOI : $10.4000 /$ assr. 21540

ISSN : $1777-5825$

Éditeur

Éditions de l'EHESS

Édition imprimée

Date de publication : 31 décembre 2009

ISBN : 978-2-7132-2218-4

ISSN : 0335-5985

\section{Référence électronique}

Regis Le Mer, «Maya burger, Claude calame, (éds.), Comparer les comparatismes. Perspectives sur I'histoire et les sciences des religions ", Archives de sciences sociales des religions [En ligne], 148 | octobre-décembre 2009, mis en ligne le 03 décembre 2013, consulté le 10 décembre 2020. URL http://journals.openedition.org/assr/21540; DOI : https://doi.org/10.4000/assr.21540 


\section{Maya BURGER, Claude CALAME, (éds.), Comparer les comparatismes. Perspectives sur l'histoire et les sciences des religions}

Paris, Milan, Edidit Archè, coll. « Histoire de l'histoire des religions », 2, 2006, 238 p.

Regis Le Mer

\section{RÉFÉRENCE}

Maya BURGer, Claude CALAmE, (éds.), Comparer les comparatismes. Perspectives sur l'histoire et les sciences des religions, Paris, Milan, Edidit Archè, coll. « Histoire de l'histoire des religions », 2, 2006, $238 \mathrm{p}$.

$148-30$

Le titre Comparer les comparatismes semble faire écho à un ouvrage paru au Seuil en 2000 «Comparer l'incomparable» de Marcel Détienne, considéré en son temps comme polémique - sinon pamphlétaire - par rapport à une école comparatiste que l'auteur avait lui-même co-fondée avec Jean-Pierre Vernant et Pierre Vidal-Naquet. Comparer les comparatismes est la seconde livraison d'une nouvelle collection « Histoire de l'histoire des religions" nous plaçant donc d'emblée dans une dimension qui se veut historiographique. Il réunit dix contributions nées d'une journée d'études sur le comparatisme et ses méthodes, datant de novembre 2004. Cette journée plaçait au centre de ses débats la réflexion sur les pratiques de comparaison en sciences humaines. Plus précisément, les échanges étaient centrés sur les différentes manières de concevoir et de pratiquer aujourd'hui la comparaison dans les sciences des religions.

Le comparatisme permet de pallier à l'enfermement disciplinaire pour, au contraire, rallier l'interdisciplinarité. Allant plus loin, l'introduction explique que «l'antidote à 
ces replis disciplinaires et institutionnels ne peut résider que dans une démarche comparative repensée en fonction des défis nouveaux, épistémologiques et historiques, auxquels les sciences humaines sont confrontées » (p. 7). Il y a également une volonté affirmée - et légitime - de distinguer la discipline historique et l'étude scientifique des religions à l'approche théologique, dans un contexte où le religieux s'affirme toujours davantage. Il est vrai qu'étudier la religion grecque antique offre une distanciation que l'on n'a pas forcément avec l'étude du catholicisme ou de l'islam.

De manière générale, les études comparatives rassemblées dans cet ouvrage mettent en perspective des éléments forts dissemblables, considérant que le comparatisme doit être réalisé dans le contraste, dans le différentiel. Il s'agit d'être attentif aux différences autant et plus qu'aux similitudes. On peut malgré tout s'interroger sur la méthodologie. Peut-on tout comparer? Mais que comparer? Faut-il faire du comparatisme pour faire du comparatisme? Mettons l'accent sur les articles les plus représentatifs de l'ouvrage.

4 La première étude d'Yvan Bubloz fait quelques rappels historiographiques bienvenus, quand la deuxième, de Nicola Gasbarro, réfléchit davantage sur des points méthodologiques de l'histoire des religions italiennes et globalement de l'apport de Lévi-Strauss dans cette discipline. Une étude de Philippe Bornet met en perspective l'hospitalité et la pratique des sacrifices dans les textes du judaïsme rabbinique et du brahmanisme ancien. Armin W. Geertz analyse la « prière » qui doit être pensée comme une catégorie scientifique à part entière. La prière est ce qui est le plus généralisé dans les religions et constitue en ce sens un point d'achoppement intéressant. Au-delà de l'étude de la "prière ", l'auteur a un projet ambitieux de science analytique comparée des religions dans laquelle il semble penser que beaucoup d'erreurs d'interprétations ont été faites dans le passé et il propose une méthodologie pour ré-analyser les choses. Un article de Maya Burger propose un comparatisme pour comprendre les échanges entre l'Inde et l'Occident à propos du yoga indien. Ce comparatisme avec la "pratique des regards croisés » assure une approche efficace de l'histoire moderne du yoga et de son expansion. Pour l'auteure, seul ce "va-et-vient" comparatif entre les deux traditions indiennes et européennes permet de saisir les processus dans toutes leurs dimensions.

On peut reprocher à ces études d'ouvrir en quelques pages des problématiques qu'un ouvrage entier ne suffirait pas à couvrir à l'instar de cette courte analyse de Philippe Bornet évoquée plus haut, et qui fait, par ailleurs, l'objet d'une thèse de doctorat. La comparaison a été utilisée depuis plusieurs décennies par différentes écoles et dans différents champs d'études, même si le champ du religieux a été prégnant: structuralistes, puis phénoménologistes, évolutionnistes s'y sont essayés. On pense à Lévi-Strauss et à Dumézil, puis à Vernant et Vidal-Naquet.

6 Ce recueil d'articles, sur un même sujet mais pourtant très différents dans leurs approches et conclusions, ainsi que dans leur intérêt et rigueur, engendre des interrogations. Un renouveau du comparatisme et de la méthode comparatiste, tel que veulent l'initier ces études, est-il possible? envisageable? souhaitable? pertinent? N'a-t-on pas fait le tour de cette méthode, de la construction intellectuelle qu'elle a proposée et des modèles efficaces qu'elle a développés pour analyser le phénomène religieux? 